\title{
Nerve Growth Factor and Semaphorin 3A Signaling Pathways Interact in Regulating Sensory Neuronal Growth Cone Motility
}

\author{
Vassil D. Dontchev ${ }^{2}$ and Paul C. Letourneau ${ }^{1}$ \\ ${ }^{1}$ Department of Neuroscience, University of Minnesota, Minneapolis, Minnesota 55455, and ${ }^{2}$ Department of Anatomy \\ and Histology, Medical University-Sofia, Sofia, 1431 Bulgaria
}

\begin{abstract}
Neurotrophins and semaphorin $3 \mathrm{~A}$ are present along pathways and in targets of developing axons of dorsal root ganglion (DRG) sensory neurons. Growth cones of sensory axons are probably regulated by interaction of cytoplasmic signaling triggered coincidentally by both types of guidance molecules. We investigated the in vitro interactions of neurotrophins and semaphorin 3A (Sema3A) in modulating growth cone behaviors of axons extended from DRGs of embryonic day 7 chick embryos. Growth cones of DRGs raised in media containing $10^{-9}$ M NGF or BDNF were more resistant to Sema3A-induced growth cone collapse than when DRGs were raised in $10^{-11} \mathrm{M}$ NGF. After overnight culture in $10^{-11} \mathrm{M}$ NGF, a $1 \mathrm{hr}$ treatment with $10^{-9} \mathrm{M}$ NGF or BDNF was sufficient to increase growth cone resistance to Sema3A-induced collapse. This neurotrophinmediated decrease in the collapse response of DRG growth cones was not associated with reduced expression on growth
\end{abstract}

cones of the Sema3A-binding protein neuropilin-1. A series of pharmacological studies followed. Phosphatidylinositol 3 kinase activity is not required for these effects of NGF. The effects of inhibitors and activators of protein kinase $A(P K A)$ indicate that PKA activity is involved in NGF modulation of Sema3Ainduced growth cone collapse. The effects of inhibitors and activators of PKG indicate that PKG activity is involved in Sema3A-induced growth cone collapse. The effects of inhibitors also indicate that Rho-kinase activity is involved in Sema3A-induced growth cone collapse. These results are consistent with the idea that growth cone responses to an individual guidance cue depend on coincident signaling by other guidance cues and by other regulatory pathways.

Key words: neurotrophin; semaphorin3A; protein kinase A; protein kinase G; ROCK kinase; growth cone
Developing axons are guided to their targets by extracellular physical and molecular cues (Muller, 1999). These molecular cues have positive or negative effects on growth cone motility as they bind to surface receptors and trigger intracellular pathways that regulate cytoskeletal components underlying growth cone motility (Letourneau, 1996). In developing tissues, growth cones simultaneously encounter multiple guidance cues; thus, growth cone behaviors reflect the integration of signaling by multiple cues. Furthermore, responses to a cue may vary, depending on other cues and coincident signaling (Ming et al., 1997; Song et al., 1998; Hopker et al., 1999; Song and Poo, 1999; Stein and TessierLavigne, 2001).

Sensory neurons of the dorsal root ganglion (DRG) extend peripheral processes to skin, muscle, and other organs, and DRG central processes make synapses in the spinal cord. The neurotrophin NGF and semaphorin 3A (Sema3A) regulate the in vitro motility of DRG growth cones and regulate in vivo axonal morphogenesis, as shown by experimentation and by analyses of mice with mutations for NGF, Sema3A, and the neuropilin-1 Sema3A receptor (Martin et al., 1989; Taniguchi et al., 1997; Patel et al., 2000; Tucker et al., 2001). NGF and Sema3A are present in peripheral path-

Received Feb. 15, 2002; revised April 29, 2002; accepted May 8, 2002.

This work was supported by National Institutes of Health (NIH) Grant HD19950 (P.C.L.), National Science Foundation Grant IBN-0080932 (P.C.L.), a grant from the NIH/Fogarty International Center (V.D.D. while in the Letourneau laboratory), and a Minnesota Medical Foundation grant. Florence Roche and Eric Veien provided valuable technical assistance, and Dr. Gianluca Gallo provided valuable comments on this manuscript.

Correspondence should be addressed to Paul C. Letourneau, Department of Neuroscience, University of Minnesota, 6-145 Jackson Hall, 321 Church Street Southeast, Minneapolis, MN 55455. E-mail: letour@lenti.med.umn.edu.

Copyright (C) 2002 Society for Neuroscience $0270-6474 / 02 / 226659-11 \$ 15.00 / 0$ ways and in targets of DRG axons (Elkabes et al., 1994; Messersmith et al., 1995; Wright et al., 1995; Giger et al., 1996; Puschel et al., 1996; Shepherd et al., 1996, 1997; White et al., 1996; Fu et al., 2000; Cahoon-Metzger et al., 2001). This codistribution prompted us to examine whether NGF and Sema3A interact in regulating DRG growth cones.

NGF promotes differentiation, survival, and morphogenesis of trkA-expressing sensory neurons (Snider, 1994). Application of NGF in vitro locally stimulates growth cone migration and axonal branching (Gallo et al., 1997; Gallo and Letourneau, 1998). NGF binding to trkA and p75 receptors activates numerous signaling pathways (Lee et al., 2001; Patapoutian and Reichardt, 2001), and NGF regulation of growth cone motility involves phospholipase $\mathrm{C}$, phosphatidylinositol 3 kinase (PI3 kinase), and cAMP pathways (Gallo and Letourneau, 1997; Song et al., 1998; Cai et al., 1999; Ming et al., 1999; Song and Poo, 1999; Zhang et al., 1999). Sema3A is concentrated in regions avoided by NGF-responsive DRG axons, and soluble Sema3A collapses NGF-responsive DRG growth cones (Luo et al., 1993; Shepherd et al., 1997; Tuttle and O'Leary, 1998). Signaling by Sema3A through the neuropilin-1-plexin complex is not well understood, although reports implicate cGMP levels and Rac1 and RhoA GTPases in Sema3A signaling (Jin and Strittmatter, 1997; Kuhn et al., 1999; Vastrik et al., 1999; Nakamura et al., 2000; Rhom et al., 2000).

We investigated interactions of NGF and Sema3A signaling in regulating chick DRG growth cones. Elevated levels of NGF reduced the collapse of DRG growth cones by Sema3A. Pharmacological studies indicated opposite roles for protein kinase A (PKA) and PKG in mediating signaling by these molecules. Our results support the idea that responses of growth cones to guid- 
ance cues depend on signaling from other cues and activities of second messengers (Hopker et al., 1999; Song et al., 1999; Zou et al., 2000; Stein and Tessier-Lavigne, 2001).

\section{MATERIALS AND METHODS}

Materials. NGF was obtained from R \& D Systems (Minneapolis, MN). BDNF and neurotrophin 3 (NT3) were generously provided by Regeneron Pharmaceuticals (Tarrytown, NY). 8-bromo-cAMP, 8-bromocGMP, 1H-[1,2,4]-oxadiazolo-[4,3- $\alpha$-quinoxalin-1-one (ODQ), KT5720, KT5823, Sp-isomer (Sp)-cAMP, wortmannin, 2-(4-morpholinyl)-8phenyl-4H-1 benzopyran-4-one (LY294002), (R)-(+)-trans- $N$-(4-pyridyl)-4(1-aminoethyl)-cyclohexanecarboxamide (Y27632), and (5-isoquinolinesulfonyl)homopiperazine (HA1077) were purchased from Biomol (Plymouth Meeting, PA). PKI and 3-(5'-hydroxymethyl-2'-furyl)-1-benzylindazole (YC-1) were purchased from Calbiochem (La Jolla, CA). Purified Sema3A and human embryonic kidney 293 (HEK293) cells transfected to produce and secrete Sema3A were generously provided by Drs. Yuling Luo and Sheldon Ng (Exelixis, Inc., South San Francisco, CA). Solutions of drugs were prepared in water or in DMSO and were aliquoted. Drugs were used immediately or stored in at $-20^{\circ} \mathrm{C}$ no more than 3 months, depending on the drug stability. On the day of an experiment, fresh solutions in culture medium were prepared.

$D R G$ cultures. Culture dishes were treated overnight with $10 \mu \mathrm{g} / \mathrm{ml}$ laminin. Explants of embryonic day 7 (E7) chick DRGs were cultured overnight in a warmed, humidified incubator in $2 \mathrm{ml}$ of F-12 medium (Invitrogen, San Diego, CA) buffered with $10 \mathrm{~mm}$ HEPES and with supplements (in $\mu \mathrm{g} / \mathrm{ml}$ : 5 transferrin, 40 sodium pyruvate, 5 phosphocreatine, 5 progesterone, and $5 \mathrm{Na}$ selenite) and neurotrophins (BDNF, NGF, or NT3). DRG explants were experimentally treated with neurotrophins and drugs in several ways: (1) explants were cultured overnight in $10^{-11}, 10^{-10}$, or $10^{-9} \mathrm{M}$ neurotrophin before the addition of Sema3A or control medium for $30 \mathrm{~min}$; (2) explants were cultured overnight in $10^{-11} \mathrm{M}$ NGF, BDNF, or NT3, and on the next day, $10^{-9} \mathrm{M}$ NGF, BDNF, or NT3 was added to some dishes for $1 \mathrm{hr}$, followed by the addition of Sema3A for $30 \mathrm{~min}$; (3) explants were cultured overnight in $10^{-11} \mathrm{M}$ NGF, and on the next day, $10^{-9} \mathrm{M}$ NGF was added to some dishes for $1 \mathrm{hr}$, followed by addition of pharmacological inhibitors to some dishes for another hour and then by Sema3A for $30 \mathrm{~min}$; and (4) explants were cultured overnight in $10^{-11} \mathrm{M} \mathrm{NGF}$, and on the next day, a drug was added to some dishes for $1 \mathrm{hr}$, followed by addition of $10^{-9} \mathrm{M}$ NGF for another hour and then by Sema3A for $30 \mathrm{~min}$.

All collapse assays were performed similarly. Purified Sema3A or conditioned medium from Sema3A-transfected 293 cells was added for $30 \mathrm{~min}$, followed by fixation with $0.5 \%$ glutaraldehyde in PBS for $30 \mathrm{~min}$. The fixed DRGs were then viewed by phase contrast optics with a $20 \times$ objective of a Nikon Diaphot inverted microscope, and the morphology of randomly selected axonal endings was scored as either a normal growth cone with lamellipodia and filopodia or a collapsed growth cone (a tapered axonal terminal without spread lamellipodia or less than three filopodia; Luo et al., 1993).

Table 1 presents data on the numbers of experiments performed and the total numbers of growth cones classified as collapsed or not collapsed for each experimental study. Statistical significance of the differences between sample populations in each experimental study was analyzed with the $\chi^{2}$ test.

Time-lapse videomicroscopy. Dishes for videomicroscopy were prepared (Gallo et al., 1997) and coated with $10 \mu \mathrm{g} / \mathrm{ml} \mathrm{laminin} \mathrm{overnight.} \mathrm{E7}$ DRG explants were cultured overnight in F-12 medium with a low concentration $\left(10^{-11} \mathrm{M}\right)$ of neurotrophin. After placing a dish on the warmed stage of a Zeiss (Thornwood, NY) IM35 or Olympus Optical (Tokyo, Japan) inverted microscope and waiting several minutes for recovery, additional neurotrophins, drugs, and Sema3A were added as described above. Images were saved at intervals from $15 \mathrm{sec}$ to $2 \mathrm{~min}$.

Conditioned media from Sema3A-transfected 293 cells. HEK293 cells stably transfected to express human Sema3A were prepared as described by Luo et al. (1993). The cells were maintained in MEM supplemented with $10 \%$ fetal bovine serum, $1 \mathrm{ml} / 100 \mathrm{ml}$ penicillin, streptomycin, and fungizone, $300 \mu \mathrm{l} / 100 \mathrm{ml} 100 \mathrm{mg} / \mathrm{ml}$ Geneticin, $1 \mathrm{ml} / 100 \mathrm{ml}$ L-glutamine, and $1 \mathrm{ml} / 100 \mathrm{ml} 1 \mathrm{~m}$ HEPES buffer (serum from HyClone, Logan, UT; all other medium components from Invitrogen). Conditioned medium was collected after $24-72 \mathrm{hr}$ culture of confluent cultures. Conditioned medium from several flasks was pooled, and aliquots were frozen. Once thawed, an aliquot of Sema3A-conditioned medium was used on only $1 \mathrm{~d}$. Untransfected 293 cells were cultured in the same medium without
Geneticin, and conditioned medium for control experiments was prepared similarly. Expression of Sema3A by transfected 293 cells was confirmed by immunocytochemical staining using anti-human Sema3A from Santa Cruz Biotechnology (Santa Cruz, CA). Although Sema3Atransfected cells were strongly labeled by anti-Sema3A, untransfected 293 cells were not.

Immunocytochemistry. DRG explants from E7 chick embryos were cultured on laminin-coated coverslips for $24 \mathrm{hr}$ as described above. After $24 \mathrm{hr}$ of culture, the cultures were fixed with $4 \%$ paraformaldehyde in PBS by adding the warmed fixative directly to the culture medium for 15 min, followed by immunocytochemistry. After rinsing off the fix, the cultures were quenched with $0.1 \mathrm{M}$ glycine in PBS for $15 \mathrm{~min}$, and then the neurons were blocked and permeabilized with $0.1 \%$ Triton X-100 in PBS with $1 \%$ fish gelatin for $30 \mathrm{~min}$. The fixed cells were incubated 1:100 dilutions of polyclonal antibodies against either the catalytic subunit of the $\alpha$ isoform of PKA or PKG-I $\alpha$ (both from Stressgen Biotechnologies Corp.) for $1 \mathrm{hr}$ at room temperature. Staining for tubulin was done with a 1:100 dilution of a monoclonal antibody against $\beta$-tubulin $(\beta \mathrm{III} ; \mathrm{Co}-$ vance). One percent fish gelatin was incubated together with the primary antibody. After rinsing in PBS, the samples were incubated with secondary rhodamine-conjugated goat anti-rabbit and fluorescein-conjugated goat-anti-mouse antibodies (Jackson ImmunoResearch, West Grove, PA), each diluted 1:400 in PBS with $1 \%$ fish gelatin for $1 \mathrm{hr}$ at room temperature.

Quantitation of intensity of neuropilin-1 staining. After $24 \mathrm{hr}$ of culture, the DRG cultures were fixed with $2 \%$ paraformaldehyde in PBS by adding the warmed fixative directly to the culture medium for $15 \mathrm{~min}$. After rinsing off the fix, the cultures were quenched with $0.1 \mathrm{M}$ glycine in PBS for $15 \mathrm{~min}$, and then the neurons were blocked and permeabilized with $0.1 \%$ Triton X-100 in PBS with $1 \%$ fish gelatin for 30 min. Incubation with anti-neuropilin-1 antibody (generously provided by Dr. Hajime Fugisawa, Nagoya University; Takagi et al., 1995) diluted 1:200 in fish gelatin solution was overnight at $4^{\circ} \mathrm{C}$. Staining for actin was done by adding $5 \mu \mathrm{l}$ of fluorescein-conjugated phalloidin for each $100 \mu \mathrm{l}$ of PBS with $1 \%$ fish gelatin and was incubated together with the primary antibody. After rinsing in PBS, the samples were incubated with secondary rhodamine-conjugated goat-anti-rabbit antibody (Jackson ImmunoResearch), diluted 1:400 in PBS with 1\% fish gelatin for $1 \mathrm{hr}$ at room temperature.

Slides were viewed using a fluorescence microscope (Olympus, $60 \times$ objective), and images of axons and growth cones were recorded using MetaView imaging software (Universal Imaging Corp., West Chester, PA). The image acquisition settings were kept the same for all images of one experiment. Acquisition settings were different for rhodamine (neuropilin) and fluorescein (actin) signals, and settings were set so all pixels had intensities $<90 \%$ of the maximum value (i.e., 4095).

Rhodamine signal intensity was measured using MetaView intensity measurement tools. Briefly, an entire growth cone, defined as the terminal $20 \mu \mathrm{m}$ of the distal axon, was traced with a selection tool, and an average intensity of that area was recorded. The average intensity of an identical area of the adjacent background was also recorded. The intensity of at least 30 growth cones was measured for each experimental condition. The background intensity was subtracted from the intensity of a growth cone for each individual image, and further analysis was performed using the resulting difference. Microsoft Excel was used to calculate the average intensity and SE for each experimental condition. Statistical significance of differences between populations was determined by a one-way ANOVA.

\section{RESULTS}

Table 1 summarizes all experiments and presents the total number of DRG growth cones that were scored as collapsed or not collapsed for each experimental study.

\section{Elevated neurotrophin concentrations can reduce Sema3A-induced growth cone collapse}

Explants of E7 chick DRGs were cultured overnight in media containing $10^{-11}, 10^{-10}$, or $10^{-9} \mathrm{M} \mathrm{NGF}, \mathrm{BDNF}$, or NT3. After fixation, the dishes were scored for percent collapsed growth cones under control conditions. Although most growth cones were not collapsed, overnight neurotrophin concentration did affect the percentage of growth cones that appeared collapsed under control conditions. Significantly fewer growth cones were 
Table 1. Numbers of experiments and numbers of growth cones counted in all collapse assays

No. of

experi-

ments

Figure 1. Effects of overnight neurotrophin concentration on growth cone response to Sema3A

\begin{tabular}{|c|c|c|c|c|c|c|c|}
\hline & Overnight (neurotrophin) & NGF & BDNF & NT3 & NGF & BDNF & NT3 \\
\hline 4 & $10^{-11} \mathrm{M}$ & 2607 & 296 & 1817 & 4150 & 943 & 1094 \\
\hline & $10^{-10} \mathrm{M}$ & 2382 & 755 & 1511 & 2867 & 925 & 1699 \\
\hline & $10^{-9} \mathrm{M}$ & 4041 & 1508 & 1132 & 2217 & 656 & 1830 \\
\hline
\end{tabular}

Figure 3. Effects of $1 \mathrm{hr}$ treatment with $10^{-9} \mathrm{M}$ neurotrophin after overnight in $10^{-11} \mathrm{M}$ neurotrophin on growth cone response to Sema3A

\begin{tabular}{|c|c|c|c|c|c|c|c|c|c|}
\hline & Figure3A & None & NGF & BDNF & & None & NGF & BDNF & \\
\hline \multirow[t]{2}{*}{4} & $10^{-11}$ м NGF overnight & 6735 & 526 & 1110 & & 7112 & 930 & 972 & \\
\hline & $10^{-11}$ м BDNF overnight & 419 & 926 & 726 & & 1161 & 659 & 929 & \\
\hline \multirow[t]{2}{*}{3} & Figure 3B & None & NGF & BDNF & NT3 & None & NGF & BDNF & NT3 \\
\hline & $10^{-11}$ м NGF overnight & 6735 & 526 & 1110 & 531 & 7112 & 930 & 972 & 469 \\
\hline
\end{tabular}

Figure 4. Effect of overnight neurotrophin concentration on growth cone response to increasing concentrations of Sema3A

\begin{tabular}{|c|c|c|c|c|}
\hline & Sema3A conditioned medium added $(\mu \mathrm{l} / \mathrm{ml})$ & $10^{-9} \mathrm{M}$ & $10^{-10} \mathrm{M}$ & $10^{-11} \mathrm{M}$ \\
\hline \multirow[t]{8}{*}{5} & 0 (control medium) & 2949 & 1655 & 1406 \\
\hline & 10 & 2285 & 1236 & 1268 \\
\hline & 15 & 1480 & 608 & 1073 \\
\hline & 20 & 1600 & 697 & 1025 \\
\hline & 30 & 1530 & 764 & 990 \\
\hline & 50 & 1682 & 627 & 1342 \\
\hline & 70 & 1219 & 818 & 1003 \\
\hline & 90 & 1738 & 842 & 976 \\
\hline
\end{tabular}

Figure 7. Effects of PI3 kinase inhibitors and elevated [NGF] on growth cone response to Sema3A

\begin{tabular}{|c|c|c|c|c|c|c|c|c|c|}
\hline & $\begin{array}{l}\text { Treatment after overnight } \\
\text { in } 10^{-11} \mathrm{M} \mathrm{NGF}\end{array}$ & None & Drug & $\begin{array}{l}10^{-9} \mathrm{M} \\
\mathrm{NGF}\end{array}$ & $\begin{array}{l}\text { Drug and } \\
10^{-9} \mathrm{M} \text { NGF }\end{array}$ & None & Drug & $\begin{array}{l}10^{-9} \mathrm{M} \\
\mathrm{NGF}\end{array}$ & $\begin{array}{l}\text { Drug and } \\
10^{-9} \mathrm{M} \mathrm{NGF}\end{array}$ \\
\hline 3 & LY294002 & 1051 & 772 & 828 & 1082 & 723 & 903 & 788 & 1232 \\
\hline 3 & Wortmannin & 449 & 314 & 858 & 1061 & 579 & 551 & 936 & 970 \\
\hline
\end{tabular}

Figure $9 A$. Effects of PKA activation and elevated $[\mathrm{NGF}]$ on growth cone response to Sema3A

\begin{tabular}{|c|c|c|c|c|c|c|c|c|c|}
\hline & $\begin{array}{l}\text { Treatment after overnight } \\
\text { in } 10^{-11} \mathrm{M} \mathrm{NGF}\end{array}$ & None & Drug & $\begin{array}{l}10^{-9} \mathrm{M} \\
\mathrm{NGF}\end{array}$ & $\begin{array}{l}\text { Drug and } \\
10^{-9} \mathrm{M} \text { NGF }\end{array}$ & None & Drug & $\begin{array}{l}10^{-9} \mathrm{M} \\
\mathrm{NGF}\end{array}$ & $\begin{array}{l}\text { Drug and } \\
10^{-9} \mathrm{M} \text { NGF }\end{array}$ \\
\hline 14 & 8-br-cAMP & 1195 & 3037 & 2971 & 5005 & 1877 & 2911 & 2357 & 3086 \\
\hline 7 & Sp-cAMP & 924 & 1300 & 1072 & 1196 & 1251 & 987 & 757 & 794 \\
\hline
\end{tabular}

Figure $9 B$. Effects of PKA inhibition and elevated [NGF] on growth cone response to Sema3A

\begin{tabular}{|c|c|c|c|c|c|c|c|c|c|}
\hline & $\begin{array}{l}\text { Treatment after overnight } \\
\text { in } 10^{-11} \mathrm{M} \mathrm{NGF}\end{array}$ & None & Drug & $\begin{array}{l}10^{-9} \mathrm{M} \\
\mathrm{NGF}\end{array}$ & $\begin{array}{l}\text { Drug and } \\
10^{-9} \mathrm{M} \mathrm{NGF}\end{array}$ & None & Drug & $\begin{array}{l}10^{-9} \mathrm{M} \\
\mathrm{NGF}\end{array}$ & $\begin{array}{l}\text { Drug and } \\
10^{-9} \mathrm{M} \mathrm{NGF}\end{array}$ \\
\hline 17 & КТ5720 & 1611 & 2828 & 2342 & 2156 & 2193 & 1890 & 1865 & 1720 \\
\hline 7 & PKI & 902 & 1047 & 853 & 949 & 1352 & 1001 & 617 & 552 \\
\hline
\end{tabular}

Figure $10 A$. Effects of PKG inhibition and elevated [NGF] on growth cone response to Sema3A

\begin{tabular}{|c|c|c|c|c|c|c|c|c|c|}
\hline & $\begin{array}{l}\text { Treatment after overnight } \\
\text { in } 10^{-11} \mathrm{M} \text { NGF }\end{array}$ & None & Drug & $\begin{array}{l}10^{-9}{ }^{\mathrm{M}} \\
\mathrm{NGF}\end{array}$ & $\begin{array}{l}\text { Drug and } \\
10^{-9} \mathrm{M} \text { NGF }\end{array}$ & None & Drug & $\begin{array}{l}10^{-9} \mathrm{M} \\
\mathrm{NGF}\end{array}$ & $\begin{array}{l}\text { Drug and } \\
10^{-9} \text { M NGF }\end{array}$ \\
\hline 5 & KT5823 & 1653 & 2268 & 1720 & 1967 & 1744 & 1890 & 1054 & 1565 \\
\hline 5 & ODQ & 1578 & 1692 & 1653 & 1906 & 1391 & 1694 & 927 & 1468 \\
\hline
\end{tabular}

Figure $10 B$. The effects of PKG activation and elevated $[\mathrm{NGF}]$ on growth cone response to Sema3A

\begin{tabular}{|c|c|c|c|c|c|c|c|c|c|}
\hline & $\begin{array}{l}\text { Treatment after overnight } \\
\text { in } 10^{-11} \mathrm{M} \mathrm{NGF}\end{array}$ & None & Drug & $\begin{array}{l}10^{-9}{ }^{\mathrm{M}} \\
\mathrm{NGF}\end{array}$ & $\begin{array}{l}\text { Drug and } \\
10^{-9} \mathrm{M} \text { NGF }\end{array}$ & None & Drug & $\begin{array}{l}10^{-9} \mathrm{M} \\
\mathrm{NGF}\end{array}$ & $\begin{array}{l}\text { Drug and } \\
10^{-9} \mathrm{M} \text { NGF }\end{array}$ \\
\hline 13 & 8-br-cGMP & 1560 & 1587 & 1589 & 1111 & 1536 & 1863 & 1255 & 808 \\
\hline 4 & YC-1 & 572 & 573 & 731 & 506 & 1227 & 950 & 962 & 919 \\
\hline
\end{tabular}

Figure 11. The effects of ROCK inhibition and elevated [NGF] on growth cone response to Sema3A

\begin{tabular}{|c|c|c|c|c|c|c|c|c|c|}
\hline & $\begin{array}{l}\text { Treatment after overnight } \\
\text { in } 10^{-11} \mathrm{M} \mathrm{NGF}\end{array}$ & None & Drug & $\begin{array}{l}10^{-9} \mathrm{M} \\
\mathrm{NGF}\end{array}$ & $\begin{array}{l}\text { Drug and } \\
10^{-9} \mathrm{M} \mathrm{NGF}\end{array}$ & None & Drug & $\begin{array}{l}10^{-9} \mathrm{M} \\
\mathrm{NGF}\end{array}$ & $\begin{array}{l}\text { Drug and } \\
10^{-9} \text { M NGF }\end{array}$ \\
\hline 6 & Y-27632 & 1806 & 1272 & 1450 & 966 & 1596 & 1283 & 1370 & 1581 \\
\hline 3 & HA1077 & 463 & 640 & 550 & 659 & 1152 & 930 & 676 & 526 \\
\hline
\end{tabular}




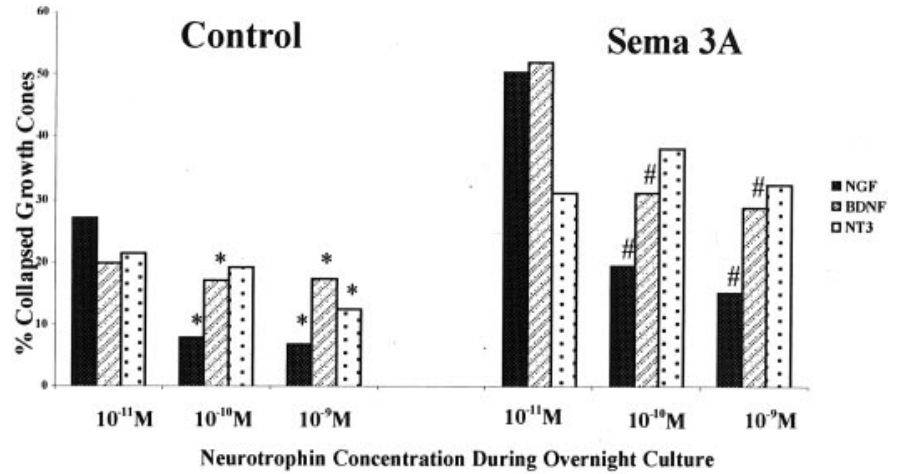

Figure 1. Effects of overnight neurotrophin concentration on growth cone response to Sema3A. DRG explants from E7 embryos were cultured overnight in media containing the neurotrophin concentrations indicated on the $x$-axis. At $24 \mathrm{hr}$, a predetermined amount of Sema3A was added to half of the dishes for $30 \mathrm{~min}$, followed by fixation with glutaraldehyde. The same volume of solution without Sema3A was added to control dishes before fixation. Each explant was scored for numbers of collapsed and intact growth cones, and the percent collapsed growth cones for each sample population is presented. ${ }^{*} p<0.01$, significantly different from $10^{-11} \mathrm{M}$ neurotrophin. ${ }^{\#} p<0.01$, significantly different from $10^{-11} \mathrm{M}$ neurotrophin and Sema3A.

collapsed in dishes cultured with $10^{-9} \mathrm{M}$ neurotrophin than with $10^{-11} \mathrm{M}$ neurotrophin (Fig. 1). This was true for all neurotrophins.

To begin analysis of interactions of neurotrophins and Sema3A in regulating DRG growth cone motility, we determined a concentration of Sema3A or Sema3A-conditioned medium that would produce $\sim 50 \%$ collapse of growth cones extended from DRG explants cultured overnight in $10^{-11} \mathrm{M}$ NGF. This was similar to one collapse unit, as defined by Luo et al. (1993). The volume of conditioned medium with this collapsing activity is similar to that reported by Luo et al. (1993), and in experiments conducted with purified Sema3A, the amount of purified Sema3A that produced $50 \%$ collapse of DRG growth cones in our assays was $4 \mathrm{ng} / \mathrm{ml}$, similar to that previously reported by Kobayashi et al. (1997). Because the purified Sema3A was available in only limited amounts, most experiments used the Sema3A-containing conditioned medium from transfected HEK293 cells.

When DRG explants were cultured overnight with $10^{-9}$ or $10^{-10} \mathrm{M}$ NGF, the growth cone collapse response to this amount of Sema3A was significantly less than observed when DRGs were cultured in $10^{-11} \mathrm{M}$ NGF (Fig. 1). Similarly, this amount of Sema3A was less effective in inducing growth cone collapse when explants were cultured overnight with $10^{-9}$ or $10^{-10} \mathrm{M}$ BDNF compared with $10^{-11} \mathrm{M}$ BDNF. In contrast, when DRGs were cultured in medium with $10^{-11}, 10^{-10}$, or $10^{-9}$ M NT3, the collapse response to Sema3A was unchanged.

Our initial experiments demonstrated that growth cones of DRG neurons cultured overnight in $10^{-10} \mathrm{M}$ or $10^{-9} \mathrm{M}$ NGF or BDNF were more resistant to Sema3A-induced collapse than growth cones extended from explants cultured with $10^{-11} \mathrm{M}$ NGF or BDNF. We next investigated whether a briefer exposure to high neurotrophin concentrations would reduce the collapse response to Sema3A. To do this, explants were cultured for $24 \mathrm{hr}$ with $10^{-11} \mathrm{M} \mathrm{NGF}$ or BDNF, and then the neurotrophin concentration of the medium was elevated to $10^{-9} \mathrm{M} \mathrm{NGF}$ or BDNF for $1 \mathrm{hr}$ before adding Sema3A for $30 \mathrm{~min}$.

We found that $1 \mathrm{hr}$ of previous exposure to $10^{-9} \mathrm{M}$ NGF or BDNF was sufficient to reduce the collapse response of DRG growth cones to Sema3A (Figs. 2, 3A). The reduction in percent collapse was greater when $10^{-9} \mathrm{M}$ NGF was added for $1 \mathrm{hr}$ before Sema3A than when $10^{-9}$ M BDNF was added, regardless of whether $10^{-11} \mathrm{M}$ NGF or BDNF was present for the first 24 hr. We also found that, unlike NGF or BDNF, $1 \mathrm{hr}$ exposure to $10^{-9}$ M NT3 had no effect on the Sema3A response of growth cones of DRG neurons raised in $10^{-11} \mathrm{M}$ NGF (Fig. $3 B$ ). Thus, elevated concentrations of NGF or BDNF can act within $1 \mathrm{hr}$ to reduce the Sema3A-induced collapse of growth cones of DRG neurons raised in $10^{-11} \mathrm{M}$ NGF or BDNF.

Our experiments showed that growth cones of DRGs cultured overnight in $10^{-10}$ or $10^{-9} \mathrm{M}$ NGF had a lower collapse response to an amount of Sema3A that caused collapse of $\sim 50 \%$ of growth cones extended from DRGs cultured overnight in $10^{-11} \mathrm{M}$ NGF. We next determined the response of growth cones from DRGs cultured in $10^{-11}, 10^{-10}$, or $10^{-9} \mathrm{M}$ NGF to increasing amounts of Sema3A. As shown in Figure 4, growth cones of DRGs cultured in $10^{-9} \mathrm{M}$ NGF were significantly less sensitive to 10,15 , or $20 \mu \mathrm{l} / \mathrm{ml} \mathrm{Sema3A-conditioned} \mathrm{medium} \mathrm{than} \mathrm{growth} \mathrm{cones} \mathrm{of}$ DRGs cultured in $10^{-11} \mathrm{M}$ NGF. However, this difference in sensitivity to Sema3A, based on neurotrophin concentration, was absent when DRGs were exposed to higher amounts of Sema3Aconditioned medium. For all of the following experiments in this study, we used concentrations of Sema-3A-conditioned medium that induced $50-70 \%$ collapse of growth cones extended from DRGs cultured overnight in $10^{-11} \mathrm{M}$ NGF.

\section{Effects of NGF concentration on intensity of neuropilin-1 staining of growth cones}

The reduction in Sema3A-induced collapse of DRG growth cones exposed to higher NGF concentrations may occur for several reasons. One possibility is that higher [NGF] may decrease expression of Sema3A receptors, thereby reducing signaling by Sema3A. We used quantitative immunocytochemistry to investigate whether expression of the Sema3A-binding receptor subunit neuropilin-1 on growth cones was reduced when DRGs were raised in $10^{-9}$ M NGF compared with $10^{-11} \mathrm{M}$ NGF. We previously used this approach to demonstrate opposite trends in temporal expression of neuropilin-1 on growth cones of DRGs raised in NT3 versus NGF (Pond et al., 2002). E7 DRGs were cultured overnight in media containing $10^{-11}, 10^{-9}, 5 \times 10^{-9}$, or $10^{-8}$ M NGF. The explants were fixed, stained with antineuropilin-1 antibody, and analyzed for levels of neuropilin-1 expression on growth cones. The results, shown in Figure 5, indicated no significant difference in intensity of neuropilin-1 staining on growth cones of DRGs raised in $10^{-11}$ versus $10^{-9} \mathrm{M} \mathrm{NGF}$, and neuropilin-1 staining intensity was actually significantly increased on growth cones of DRGs raised in $5 \times 10^{-9}$ or $10^{-8} \mathrm{M}$ NGF. Figure 6 shows images of increased intensity of neuropilin-1 immunoreactivity evident on growth cones extended from DRGs cultured in $5 \times 10^{-9}$ or $10^{-8} \mathrm{M}$ NGF compared with $10^{-9} \mathrm{M}$ NGF. These results indicate the reduction in collapse response to Sema3A when DRGs are incubated with $5 \times 10^{-9}$ M NGF is not explained by downregulation of the Sema3A receptor protein neuropilin-1.

Another possible reason that elevated [NGF] reduces the collapse response to Sema3A is that NGF signaling opposes Sema3A signaling in promoting growth cone collapse. In the following series of experiments, we used pharmacological inhibitors and activators to investigate the roles of several protein kinases that have been implicated in mediating the effects of neurotrophins and Sema3A on growth cone guidance. Each of these studies was 

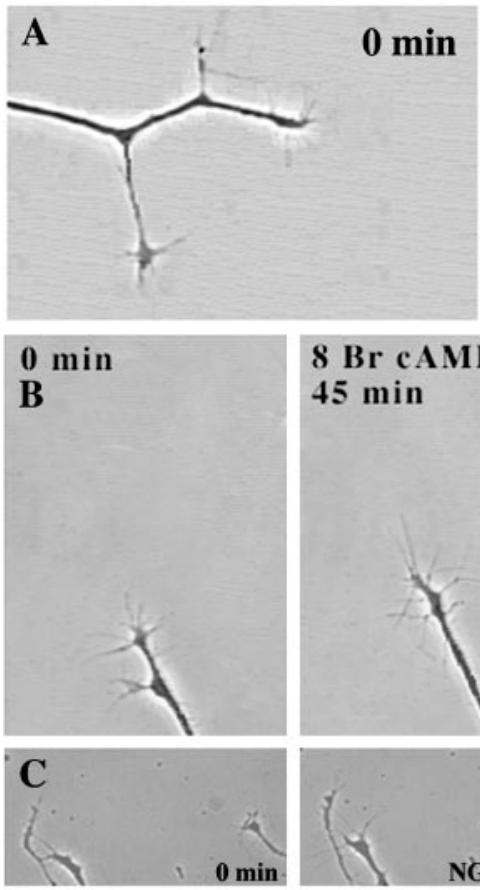
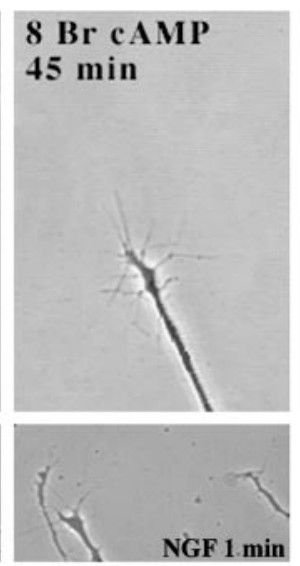
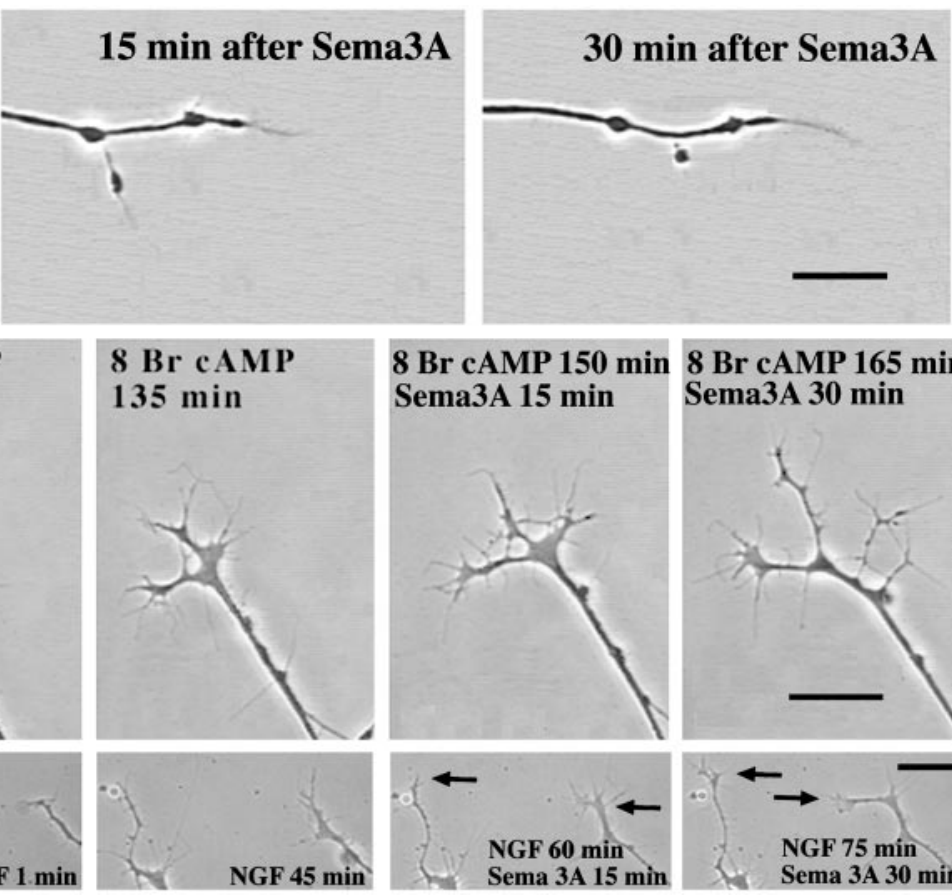
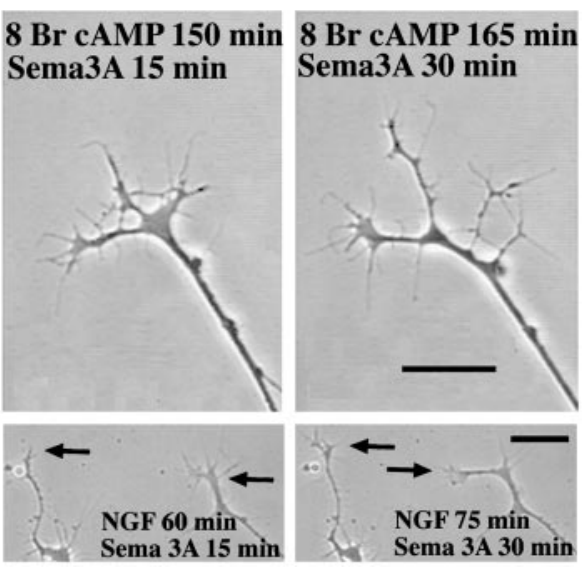

Figure 2. Effects of activation of protein kinase A and elevated [NGF] on growth cone response to Sema3A. DRG explants were cultured overnight in media containing $10^{-11} \mathrm{M} \mathrm{NGF}$, and at $24 \mathrm{hr}$ sufficient Sema3A was added to each dish to induce collapse of at least $50 \%$ of the DRG growth cones. $A$, Collapse of a growth cone raised in $10^{-11} \mathrm{M}$ NGF and exposed to Sema3A for $30 \mathrm{~min}$. B, Growth cone treated with the PKA activator 8-bromo-cAMP for $135 \mathrm{~min}$ before adding Sema3A. Growth cone motility continues after addition of Sema3A. $C$, Growth cones treated with $10^{-9} \mathrm{M}$ NGF for 45 min before adding Sema3A. Two growth cones continue to extend filopodia and advance after addition of Sema3A (arrows). Scale bar, $20 \mu \mathrm{m}$.

repeated at least three times on different dates, as indicated in Table 1.

\section{PI3 kinase activity is not required for elevated [NGF] to reduce Sema3A-induced growth cone collapse}

A signaling pathway initiated by neurotrophins that has been implicated in regulating growth cone motility involves activation of the PI3 kinase (Gallo and Letourneau, 1998; Ming et al., 1999). Two different inhibitors, wortmannin and LY294002, have been used to probe the role of PI3 kinase in cellular responses to extrinsic ligands (Davies et al., 2000). These inhibitors were used to examine the involvement of PI3 kinase in neurotrophin regulation of growth cone responses to Sema3A. The standard procedure in the following experiments with inhibitors and activators was to culture DRG explants $24 \mathrm{hr}$ with $10^{-11} \mathrm{M}$ NGF. Then, $10^{-9} \mathrm{M}$ NGF was added to some dishes for $60 \mathrm{~min}$, followed by an activator or inhibitor for $60 \mathrm{~min}$ and then by Sema3A for $30 \mathrm{~min}$, and then the cultures were fixed.

In our studies with PI3 kinase inhibitors, treatment with either drug alone led to a significant reduction of growth cone collapse in response to Sema3A, although LY294002 was more effective than wortmannin (Fig. 7). Neither inhibitor of PI3 kinase lessened the ability of $10^{-9} \mathrm{M}$ NGF to reduce growth cone collapse in response to Sema3A. The results of these experiments suggest that NGF reduction of growth cone response to Sema3A does not require the activity of PI3 kinase.

In the above experiments with PI3 kinase inhibitors, [NGF] was elevated to $10^{-9} \mathrm{M}$ for $60 \mathrm{~min}$ before adding drugs. This treatment would allow 60 min of signaling by elevated [NGF] before addition of the drug. In the next series of experiments, we added the PI3 kinase inhibitor LY294002 both before elevating [NGF] to block all PI3 kinase signaling and after elevation of [NGF]. We found that the effects of LY294002 were the same whether it was added before or after elevation of $[\mathrm{NGF}]$. The $58 \%$ collapse response to Sema3A was reduced to $31 \%$ when $10^{-9}$ M NGF was added before Sema3A, to $23 \%$ when addition of $10 \mu \mathrm{M} \mathrm{LY} 294002$ preceded $10^{-9} \mathrm{M}$ NGF, and to $20 \%$ when $10^{-9} \mathrm{M}$ NGF preceded $10 \mu \mathrm{M}$ LY294002.

\section{PKA activity is involved in NGF modulation of Sema3A-induced growth cone collapse}

It has been proposed that the cAMP-regulated PKA and cGMPregulated $\mathrm{PKG}$ modulate growth cone responses to many extrinsic molecules that regulate growth cone navigation (Song and Poo, 1999). Thus, our next experiments determined the effects of activators and inhibitors of these two kinases on NGF modulation of growth cone responses to Sema3A. We first performed immunocytochemistry using commercially available polyclonal antibodies to determine whether PKA and the PKG-I isoform are present in growth cones of E7 DRG neurons. Western blot analysis of chick embryo brain proteins separated by SDS-PAGE showed that these antibodies specifically recognized chick proteins of the expected approximate molecular weights of 53 and 75 $\mathrm{kDa}$. Figure 8 presents images that indicate robust staining of DRG growth cones for both PKA and PKG.

The first series of experiments tested the effects of activation of PKA by adding the cAMP analogs 8-bromo-cAMP and Sp-cAMP (Fig. 9A). We found that the addition of either PKA activator alone significantly reduced the growth cone collapse response to Sema3A (Fig. 2B). Furthermore, when both PKA activation and elevation of $[\mathrm{NGF}]$ preceded the addition of Sema3A, the reduction in collapse response to Sema3A was even greater.

Next we investigated the effect of inhibition of PKA activity on neurotrophin modulation of growth cone responses to Sema3A. 

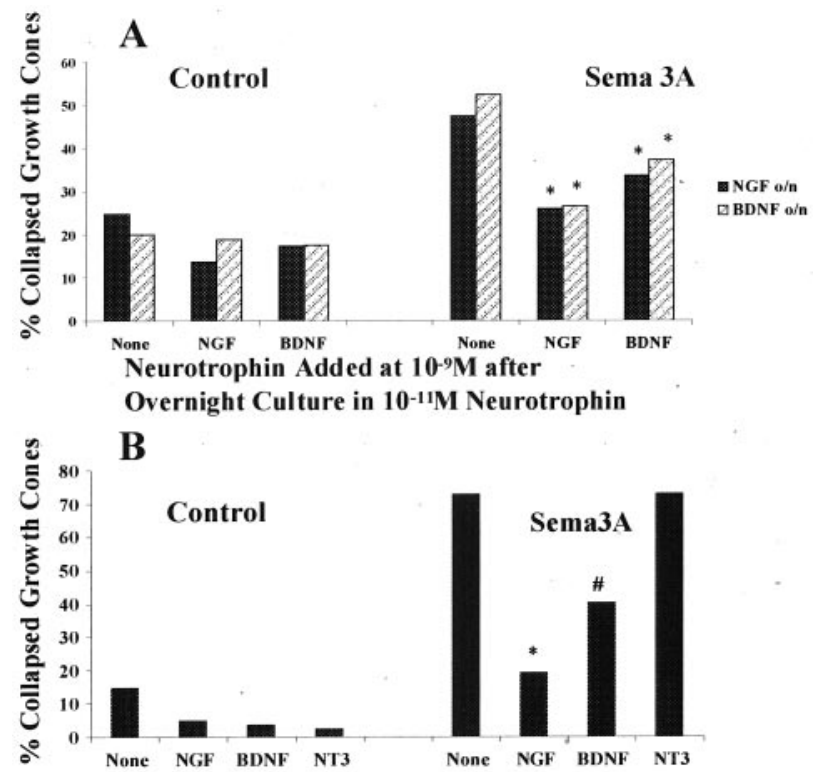

Additional Treatment with $10^{-9} \mathrm{M}$ Neurotrophin after Overnight Culture in $\mathbf{1 0}^{-11} \mathrm{M}$ Neurotrophin

Figure 3. Effects of $1 \mathrm{hr}$ culture with $10^{-9} \mathrm{M}$ neurotrophin on growth cone response to Sema3A. A, DRG explants were cultured overnight in media containing $10^{-11} \mathrm{M}$ NGF or BDNF. At $24 \mathrm{hr}$, the neurotrophin concentration in some dishes was elevated to $10^{-9} \mathrm{M}$ by addition of NGF or BDNF, as indicated. After $1 \mathrm{hr}$ with elevated neurotrophin, Sema3A or an equal volume of control medium was added for $30 \mathrm{~min}$, followed by fixation. The percent collapsed growth cones for each sample population is presented. $o / n$, Overnight. ${ }^{*} p<0.01$, significantly different from $10^{-11} \mathrm{M}$ neurotrophin and Sema3A. B, DRG explants were cultured overnight in media containing $10^{-11} \mathrm{M}$ NGF. At $24 \mathrm{hr}$, neurotrophins were added to some dishes to elevate the concentration to $10^{-9} \mathrm{M}$, as indicated. After 1 hr with elevated neurotrophin, Sema3A or an equal volume of control medium was added for $30 \mathrm{~min}$, followed by fixation. The percent collapsed growth cones for each sample population is presented. ${ }^{*} p<0.01$, significantly different from Sema3A. ${ }^{\#} p<0.01$, significantly different from Sema3A and $10^{-9} \mathrm{M}$ NGF.

Two different inhibitors of PKA activity were used in these studies (Fig. 9B). When PKA was inhibited with KT5720 before adding Sema3A (Davies et al., 2000), the collapse response to Sema3A was not significantly changed. However, inhibition of PKA by KT5720 did significantly diminish the ability of elevated [NGF] to reduce Sema3A-induced growth cone collapse. The second inhibitor that we used was a specific PKA inhibitor, a myristolated form of PKI (Walsh and Glass, 1991). We found that the previous addition of PKI enhanced the collapse of NGFcultured DRG growth cones in response to Sema3A. We also found that the addition of PKI greatly decreased the effect of $10^{-9}$ M NGF in reducing Sema3A-induced growth cone collapse. These experiments indicate that activity of PKA is required for NGF signaling to modify growth cone collapse responses to Sema3A. When PKA was inhibited, NGF-mediated reduction of the collapse response was less effective, and under conditions that activate PKA, the effects of elevated NGF were enhanced.

In the above experiments using blockers of PKA activity, [NGF] was elevated to $10^{-9} \mathrm{M}$ for $60 \mathrm{~min}$ before adding the drugs. This sequence of treatment would allow $60 \mathrm{~min}$ of signaling by elevated [NGF] before addition of a PKA inhibitor. In the next series of experiments, we added the PKA inhibitor PKI both before elevating [NGF] to block all signaling that might involve PKA activity and after elevation of $[\mathrm{NGF}]$. We found that the

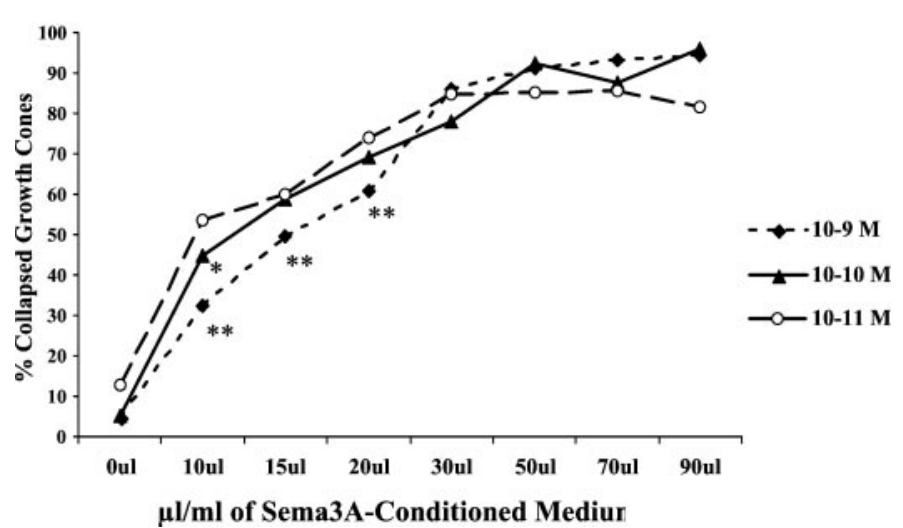

Figure 4. Effect of overnight neurotrophin concentration on growth cone response to increasing concentrations of Sema3A. DRG explants were cultured overnight in media containing the concentrations of NGF indicated in the key. At $24 \mathrm{hr}$, Sema3A was added for $30 \mathrm{~min}$ in the amounts indicated on the $x$-axis, followed by fixation. The percent collapsed growth cones for each sample population is presented. ${ }^{*} p<0.0001$, significantly different from $10^{-11} \mathrm{M}$ NGF. ${ }^{* *} p<0.0001$, significantly different from $10^{-10}$ and $10^{-11} \mathrm{M} \mathrm{NGF}$.

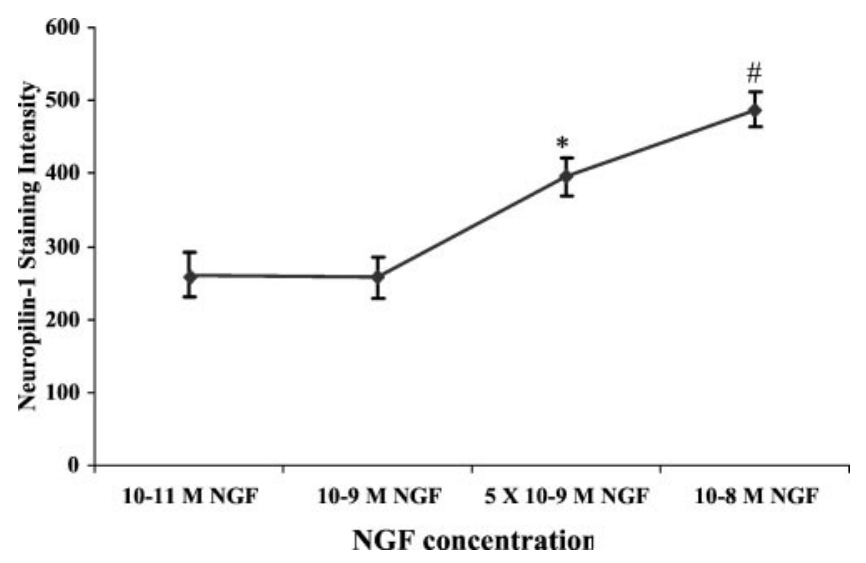

Figure 5. Intensity of anti-neuropilin-1 staining on growth cones cultured in different neurotrophin concentrations. DRG explants were cultured overnight in media containing NGF at the concentrations indicated on the $x$-axis. The explants were fixed and stained with anti-neuropilin-1, and the immunofluorescence staining intensity was determined, as described in Materials and Methods. Data are mean \pm SEM for each sample population. ${ }^{*} p<0.01$, significantly different from $10^{-9}$ M NGF. ${ }^{\#} p<$ 0.001 , significantly different from $5 \times 10^{-9} \mathrm{M}$ NGF. At least 60 growth cones were analyzed at each NGF concentration.

effects of PKI were the same whether it was added before or after [NGF ]elevation. The ability of $10^{-9}$ M NGF to reduce the $69 \%$ sema3A collapse response to $40 \%$ collapse was diminished to the same extent whether PKI was added before (58\% collapsed) or after (62\% collapsed) elevating [NGF] to $10^{-9} \mathrm{M}$ NGF.

\section{PKG activity is involved in Sema3A-induced growth cone collapse}

The cGMP-regulated kinase PKG has been implicated in mediating growth cone responses to Sema3A. Thus, we investigated the effects of manipulations that may affect the activity of PKG on chick DRG growth cone responses to Sema3A. First, we examined the effects of a PKG inhibitor, the drug KT5823 (Hidaka and Kobayashi, 1992; Firestein and Bredt, 1998). We found that the previous addition of KT5823 significantly reduced the percentage of DRG growth cones that collapsed in response to Sema3A (Fig. 

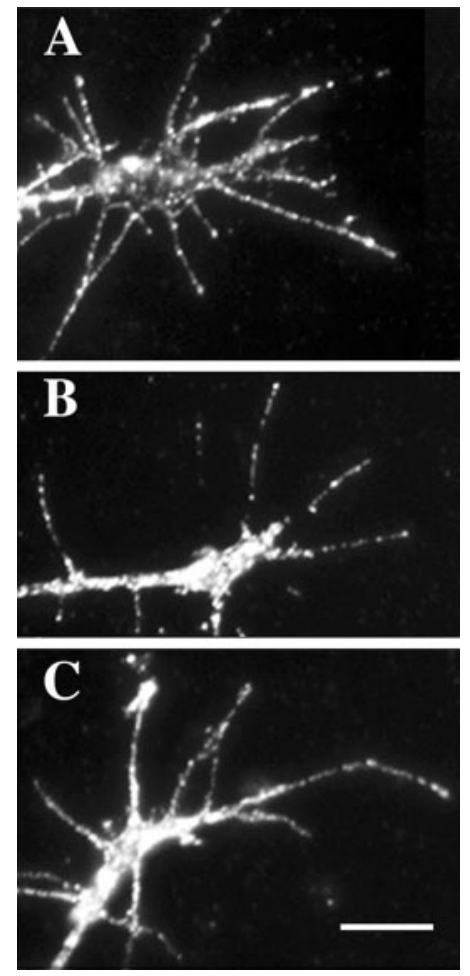

Figure 6. Anti-neuropilin-1 staining of growth cones extended from DRGs cultured overnight in $10^{-9} \mathrm{M}$ NGF $(A), 5 \times 10^{-9} \mathrm{M} \mathrm{NGF}(B)$, and $10^{-8}$ M NGF $(C)$. Fluorescent anti-neuropilin-1 staining is more intense on growth cones raised in $5 \times 10^{-9}$ or $10^{-8} \mathrm{M}$ NGF. Scale bar, $10 \mu \mathrm{m}$.

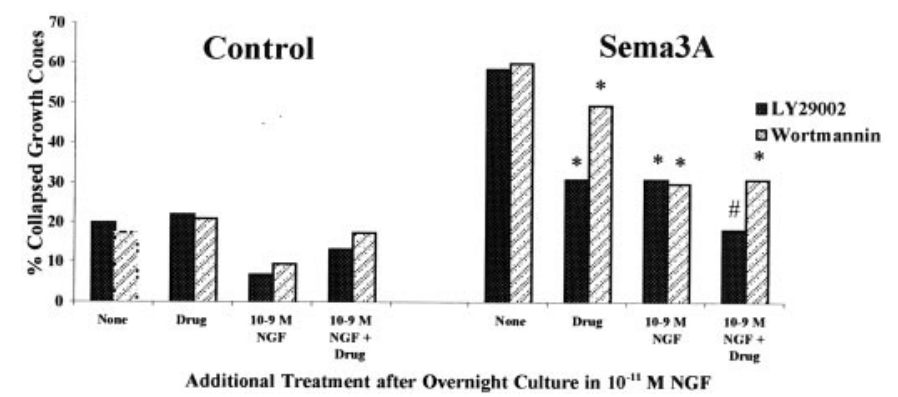

Figure 7. Effects of inhibition of PI3 kinase and elevated [NGF] on growth cone response to Sema3A. DRG explants were cultured overnight in media containing $10^{-11} \mathrm{M}$ NGF. At $24 \mathrm{hr}$ [NGF] in some dishes was elevated to $10^{-9} \mathrm{M}$ for $60 \mathrm{~min} ; 100 \mathrm{nM}$ wortmannin or $10 \mu \mathrm{M}$ LY294002 was added to some dishes for another $60 \mathrm{~min}$; and then Sema3A or control medium was added for $30 \mathrm{~min}$, followed by fixation. The percent collapsed growth cones in each sample population is presented. ${ }^{*} p<0.01$, significantly different from Sema3A. ${ }^{*} p<0.01$, significantly different from $10^{-9}$ M NGF and Sema3A.

$10 A$ ). When KT5823 pretreatment was combined with the previous elevation of $\left[\mathrm{NGF}\right.$ ] to $10^{-9} \mathrm{M}$, the collapse response to Sema3A was nearly eliminated compared with explants not exposed to Sema3A. Another manipulation that might reduce PKG activity is to inhibit soluble guanylyl cyclase, which would lead to reduced cytoplasmic [cGMP]. We added the selective guanylyl cyclase inhibitor ODQ (Garthwaite et al., 1995) before the addition of Sema3A. Treatment with ODQ alone significantly reduced the collapse response to Sema3A, and, similar to the effects of the PKG inhibitor KT5823, the combined pretreatment with ODQ and $10^{-9} \mathrm{M}$ NGF nearly eliminated any response to Sema3A.
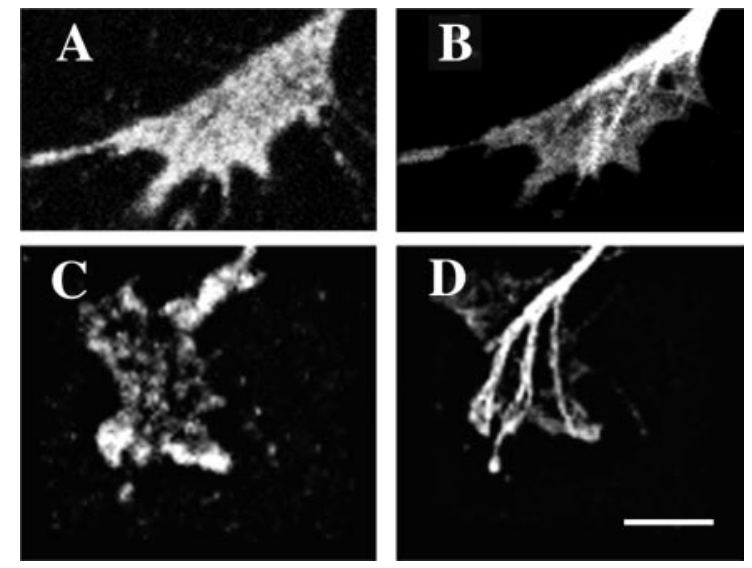

Figure 8. Immunocytochemical labeling of DRG growth cones with antibodies against the catalytic unit of PKA $(A)$ and PKG-I $(C)$. These growth cones were also labeled with anti- $\beta$-tubulin to label microtubules $(B, D)$. Staining for PKA and PKG is present in the motile peripheral domain of the growth cones. Scale bar, $10 \mu \mathrm{m}$.

To examine the effects of activation of $\mathrm{PKG}$, we added the cGMP analog 8-bromo-cGMP before addition of Sema3A (Fig. $10 B)$. We found that the addition of 8-bromo-cGMP alone induced a significant amount of growth cone collapse, and this was not attenuated by previous elevation of $[\mathrm{NGF}]$ to $10^{-9} \mathrm{M}$. When DRG explants were exposed to 8-bromo-cGMP and then Sema3A, the incidence of growth collapse was significantly higher than when explants were treated with Sema3A alone, and the elevation of $[\mathrm{NGF}]$ to $10^{-9} \mathrm{M}$ did not reduce this extensive growth cone collapse. Thus, activity of the kinase PKG does seem involved in a mechanism of growth cone collapse. Another means to activate PKG is to stimulate guanylate cyclase activity, such as with the drug YC-1 (Ko et al., 1994). Similar to the effect of adding 8-bromo-cGMP, treatment with YC-1 alone produced a significant increase in growth cone collapse, and when combined with the addition of Sema3A, growth cone collapse was significantly elevated above the effect of Sema3A alone. In addition, YC-1 significantly diminished the reduction of the collapse response when [NGF] was elevated before adding Sema3A. Thus, the effects of both of these drugs indicate that PKG activity promotes collapse of chick DRG growth cones.

\section{Inhibition of ROCK kinase reduces Sema3A-induced growth cone collapse}

The final drugs that we used to investigate collapse mechanisms in DRG growth cones were two inhibitors of the Rho-activated ROCK kinase, Y27632 and HA1077 (Davies et al., 2000). ROCK kinase has been implicated in the activation of cellular contractility (Katoh et al., 2001) and in growth cone collapse and retraction in response to several extrinsic guidance factors (Kozma et al., 1997; Kranenburg et al., 1999; Nakamura et al., 2000; Wahl et al., 2000). When added before addition of Sema3A, either ROCK kinase inhibitor significantly reduced the collapse response to Sema3A, and when combined with elevation of [NGF], growth cone collapse in response to Sema3A was barely detectable (Fig. 11).

\section{DISCUSSION}

Axonal pathfinding is controlled by extracellular proteins that act through ligand-receptor signaling to regulate growth cone behaviors (Muller, 1999). Among such proteins, neurotrophins and semaphorins regulate axonal navigation and innervation by sen- 

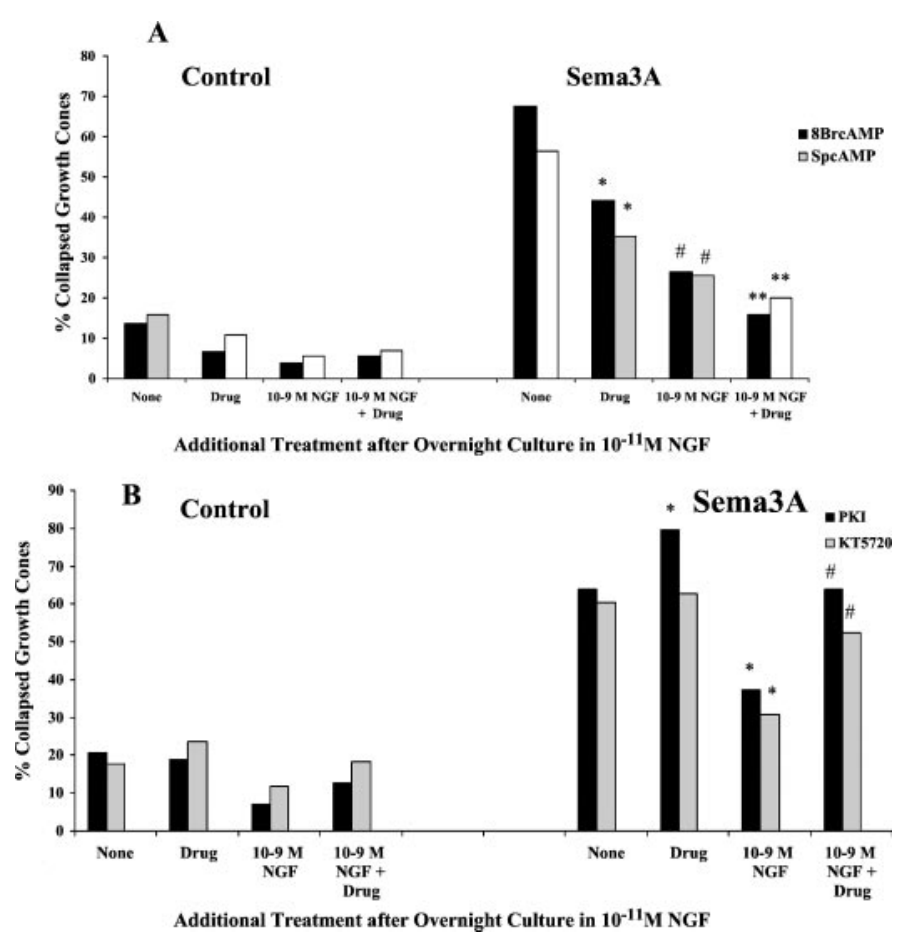

Figure 9. A, Effects of PKA activation and elevated [NGF] on growth cone response to Sema3A. DRG explants were cultured overnight in media containing $10^{-11} \mathrm{M}$ NGF. At $24 \mathrm{hr}$, [NGF] in some dishes was elevated to $10^{-9} \mathrm{M}$ for $60 \mathrm{~min} ; 2 \mathrm{mM}$ 8-bromo-cAMP or $2 \mu \mathrm{M} \mathrm{Sp}$-cAMP was added to some dishes for another $60 \mathrm{~min}$; and then Sema3A or control medium was added for $30 \mathrm{~min}$, followed by fixation. The percent collapsed growth cones for each sample population is presented. The experiments with 8-br-cAMP and Sp-cAMP were conducted at different times, with slightly different levels of collapse in response to Sema3A alone. This accounts for the different heights of bars labeled None. ${ }^{*} p<0.01$, significantly different from Sema3A. ${ }^{\#} p<0.01$, significantly different from drug and Sema3A. ${ }^{* *} p<0.01$, significantly different from $10^{-9}$ M NGF and Sema3A. B, Effects of PKA inhibition and elevated [NGF] on growth cone response to Sema3A. After overnight culture in media containing $10^{-11} \mathrm{M}$ NGF, [NGF] in some dishes was elevated to $10^{-9} \mathrm{M}$ for $60 \mathrm{~min}$; $200 \mathrm{~nm}$ KT5720 or $4 \mu \mathrm{M}$ PKI was added to some dishes for another 60 $\mathrm{min}$; and then Sema3A or control medium was added for $30 \mathrm{~min}$, followed by fixation. The percent collapsed growth cones in each sample population is presented. ${ }^{*} p<0.01$, significantly different from Sema3A. \#p $<$ 0.01 , significantly different from $10^{-9} \mathrm{M}$ NGF and Sema3A.

sory neurons. Both groups of molecules are present along pathways and in targets of sensory axons (Elkabes et al., 1994; Messersmith et al., 1995; Wright et al., 1995; Giger et al., 1996; Puschel et al., 1996; Shepherd et al., 1996; White et al., 1996; CahoonMetzger et al., 2001), suggesting that growth cone behaviors reflect integration of coincident signaling by neurotrophins and semaphorins. This idea provided the rationale for these experiments.

Our studies showed that the collapse response of sensory growth cones to Sema3A was reduced by NGF and BDNF in a concentration-dependent manner. This is like our previous finding that BDNF protects retinal growth cones from nitric oxideinduced collapse (Ernst et al., 2000). Growth cones of DRGs raised in $10^{-10}$ or $10^{-9} \mathrm{M}$ NGF or BDNF collapsed less in response to Sema3A than DRGs raised in $11^{-11} \mathrm{M}$ neurotrophin. Furthermore, $1 \mathrm{hr}$ exposure to $11^{-9} \mathrm{M}$ BDNF or NGF was sufficient to reduce collapse in response to Sema3A. Occupation of trk and p75 neurotrophin receptors would be significantly greater in $11^{-9}$ than $11^{-11} \mathrm{M}$ neurotrophin (Lee et al., 2001,
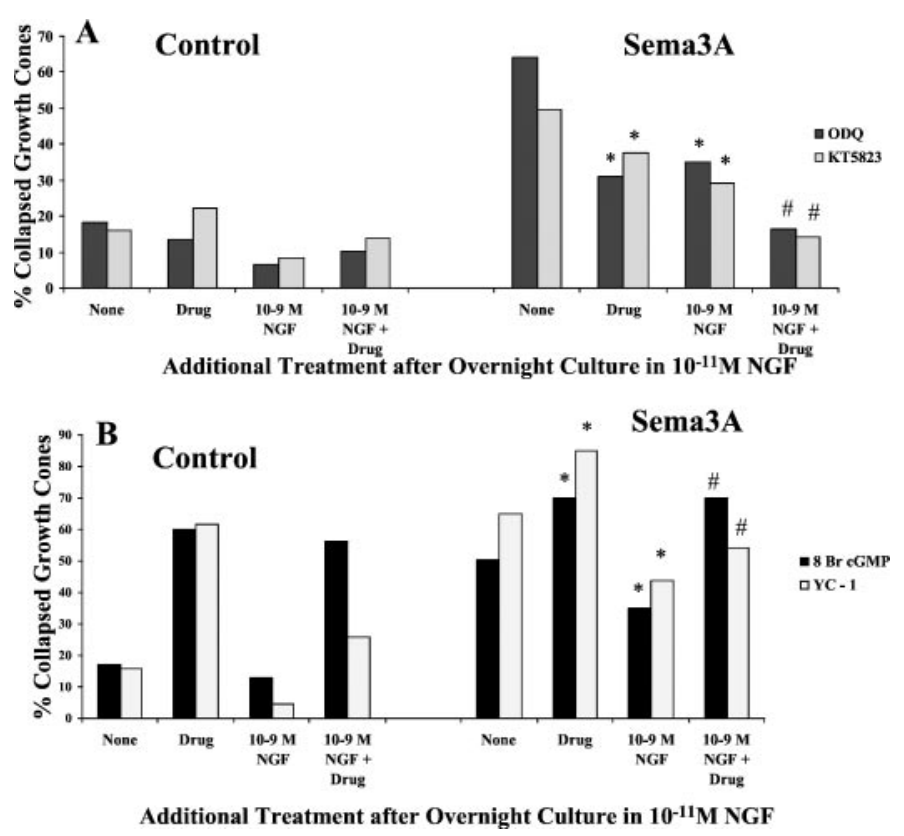

Figure 10. A, Effects of inhibition of protein kinase $\mathrm{G}$ and elevated [NGF] on growth cone response to Sema3A. DRG explants were cultured overnight in media containing $10^{-11} \mathrm{M}$ NGF. At $24 \mathrm{hr}$, [NGF] in some dishes was elevated to $10^{-9} \mathrm{M}$ for $60 \mathrm{~min}$; $1 \mu \mathrm{M}$ KT5823 or $100 \mathrm{nM}$ ODG was added to some dishes for another $60 \mathrm{~min}$; and then Sema3A or control medium was added for $30 \mathrm{~min}$, followed by fixation. The percent collapsed growth cones in each sample population is presented. The experiments with KT5823 and ODG were conducted at different times, with slightly different levels of collapse in response to Sema3A alone. This accounts for the different heights of bars labeled None. ${ }^{*} p<0.01$, significantly different from Sema3A. ${ }^{\#} p<0.01$, significantly different from $10^{-9}$ M NGF and Sema3A. B, Effects of activation of protein kinase $\mathrm{G}$ and elevated [NGF] on growth cone response to Sema3A. After overnight culture in media containing $10^{-11} \mathrm{M}$ NGF, [NGF] in some dishes was elevated to $10^{-9} \mathrm{M}$ for $60 \mathrm{~min}$; $500 \mu \mathrm{M}$ 8-bromo-cGMP or $20 \mu \mathrm{M} \mathrm{YC}-1$ was added to some dishes for another $60 \mathrm{~min}$; and then Sema3A or control medium was added for $30 \mathrm{~min}$, followed by fixation. The percent collapsed growth cones in each sample population is presented. The experiments with 8-br-cGMP and YC-1 were conducted at different times, with slightly different levels of collapse in response to Sema3A alone. This accounts for the different heights of bars labeled None. ${ }^{*} p<0.01$, significantly different from Sema3A. ${ }^{\#} p<0.01$, significantly different from $10^{-9} \mathrm{M}$ NGF and Sema3A.

Patapoutian and Reichardt, 2001), suggesting that increased neurotrophin signaling mediates effects on the response to Sema3A. Developing sensory neurons simultaneously express multiple trk receptors (Williams and Ebendal, 1995; Tuttle and O'Leary, 1998), which may explain why Sema3A responses of DRG growth cones were reduced by elevating either NGF or BDNF. When we determined responses to increasing Sema3A concentrations, we found that $10^{-9} \mathrm{M}$ NGF was effective in reducing growth cone collapse only at lower Sema3A concentrations. Perhaps high Sema3A concentrations activate collapse mechanisms too strong to be modulated by neurotrophin signaling.

Responses of growth cones extended from DRGs raised in NT3 differed from those of DRGs raised in NGF or BDNF. At E7, when we cultured DRGs, NT3-dependent DRG neurons were decreasing neuropilin-1 expression (Fu et al., 2000; Pond et al., 2002), as NT3-dependent muscle afferents invaded Sema3Acontaining ventral regions of the spinal cord (Mendelson et al., 1992; Puschel et al., 1996; Eide and Glover, 1997; Shepherd et al., 1997; Fu et al., 2000). We found that elevated [NT3] did not affect 


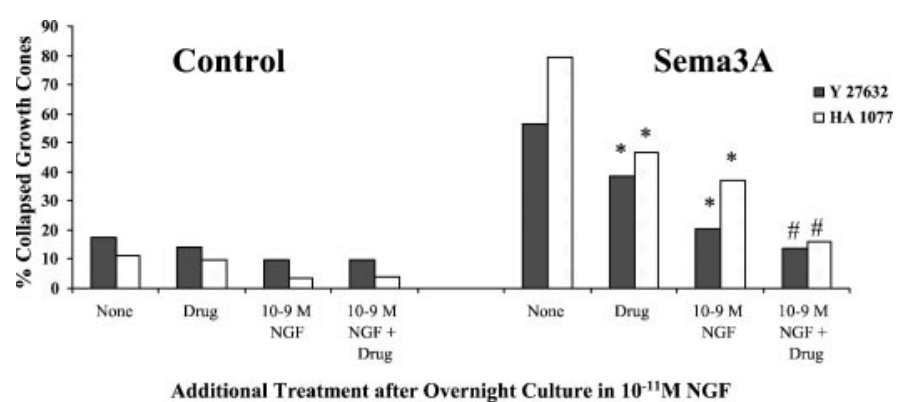

Figure 11. Effects of inhibition of RhoA-activated ROCK kinase and elevated [NGF] on growth cone response to Sema3A. DRG explants were cultured overnight in media containing $10^{-11} \mathrm{M}$ NGF. At $24 \mathrm{hr}$, [NGF] in some dishes was elevated to $10^{-9} \mathrm{M}$ for $60 \mathrm{~min}$; $10 \mu \mathrm{M} \mathrm{Y}-27632$ or $15 \mu \mathrm{M}$ HA1077 was added to some dishes for another $60 \mathrm{~min}$; and then Sema3A or control medium was added for $30 \mathrm{~min}$, followed by fixation. The percent collapsed growth cones in each sample population is presented. The experiments with Y-27632 and HA1077 were conducted at different times, with slightly different levels of collapse in response to Sema3A alone. This accounts for the different heights of bars labeled None. * $p<$ 0.01 , significantly different from Sema3A. ${ }^{\#} p<0.01$, significantly different from $10^{-9} \mathrm{M}$ NGF and Sema3A.

responses to Sem3A. Perhaps NT3 does not trigger the same signaling as NGF and BDNF. Recent publications indicate that signaling through trk and p75 receptors differs for different neurotrophins (Lee et al., 2001; Patapoutian and Reichardt, 2001).

Thus, our evidence suggests that high [NGF (and BDNF)] triggers growth cone signaling that reduces collapse responses to Sema3A. As shown in Figure 5, high [NGF] does not reduce expression of the Sema3A receptor subunit neuropilin-1 (He and Tessier-Lavigne, 1997; Kolodkin et al., 1997; Takahashi et al., 1999). Another possibility is that signaling triggered by NGF reduces the effectiveness of Sema3A signaling in causing growth cone collapse.

Several pathways activated by neurotrophins may modulate Sema3A-induced collapse (Patapoutian and Reichardt, 2001). PI3 kinase activity is required for chemotropic and branching responses to NGF (Gallo and Letourneau, 1998; Ming et al., 1999; Song and Poo, 1999). We found that PI3 kinase inhibitors wortmannin and LY294002 did not block NGF reduction of Sema3Amediated growth cone collapse, suggesting that signaling through PI3 kinase is not required for this effect of NGF. Several studies report that neurotrophins activate cAMP-dependent PKA (Knipper et al., 1993; Cai et al., 1999; Zhang et al., 1999). We also found that PKA activation mediates BDNF protection of retinal growth cones from nitric oxide (Gallo et al., 2002). Our pharmacological results with PKA modulators support involvement of PKA activity in NGF-mediated reduction of the collapse response to Sema3A. In view of the protection provided by neurotrophins against growth cone collapse induced by nitric oxide and Sema3A, a common effect of neurotrophins may be to stabilize actin filaments.

Our results indicated that cGMP-activated PKG is involved in Sema3A-induced growth cone collapse. Inhibiting PKG or guanylate cyclase reduced the collapse response to Sema3A, whereas activation of PKG or guanylyl cyclase promoted collapse. That elevation of [NGF] did not affect growth cone collapse induced by PKG activation suggests that PKG acts downstream or independently of interactions of NGF signaling with Sema3A signaling. Although cGMP is implicated in signaling to regulate growth cone guidance (Song et al., 1998; Song and Poo, 1999), it is unclear where cGMP acts. Ion channels, $\mathrm{Ca}^{2+}$ release from stores, and myosin contractility are activities that may be regulated by cGMP-dependent kinases and may affect growth cone motility (Silveira et al., 1998; Vo et al., 1998; Hoffmann, 2000). Previous reports show that chick sensory neurons contain cGMPdependent protein kinase I and are responsive to cGMP analogues (Ward et al., 1994; Qian et al., 1996; Firestein and Bredt, 1998). Our studies indicate that activation of PKA and PKG have opposite effects on growth cone collapse in response to Sema3A. A popular model proposes that PKA and PKG modulate growth cone responses in distinct pathways of guidance mechanisms (Song and Poo, 1999). Our results do not fit this model strictly, because we found that both PKA and PKG are involved in responses to Sema3A, not just PKG. However, our findings are consistent with the idea that cyclic nucleotide signaling is important in growth cone responses to guidance cues and that responses involve coincident signaling (Ming et al., 1997; Song et al., 1998).

Rho family GTPases regulate axonal morphogenesis and guidance (Gallo and Letourneau, 1998; Dickson, 2001). In PC12 cells, NGF activates Rac1, localizes Rac1 to the plasma membrane, and inhibits RhoA (Yamaguchi et al., 2001). RhoA is implicated in growth cone collapse stimulated by Sema3A, ephrin-A5, and lysophosphatidic acid (Kozma et al., 1997; Kranenburg et al., 1999; Nakamura et al., 2000; Wahl et al., 2000). Thus, downregulation of RhoA activity by NGF could contribute to reducing the effects of Sema3A. This is supported by our evidence that growth cone collapse in response to Sema3A is reduced by inhibitors of ROCK kinase. ROCK kinase is activated by RhoA and increases myosin contractility (Redowicz, 1999; Katoh et al., 2001). RhoA activity is reduced by phosphorylation of RhoA by PKA (Lang et al., 1996; Dong et al., 1998; Essler et al., 2000). This modulation of RhoA by PKA may be another site where signals activated by NGF block signaling by Sema3A.

Tuttle and O'Leary (1998) investigated effects of neurotrophin signaling on responses of chick DRG growth cones to Sema3A. The methods used here differ from those in their report. Tuttle and O'Leary (1998) used chick E6 DRGs. At E6, NT3-responsive DRG neurons express significantly higher levels of neuropilin-1 and respond differently than E7 neurons (Pond et al., 2002), which we used. Tuttle and O'Leary (1998) added $5 \times 10^{-10} \mathrm{M}$ neurotrophin (50 times what we used) to their initial media; so their studies in which BDNF was added to NGF-containing media and vice versa involved different levels of trk and p75 signaling than our study, in which DRGs were initially exposed to $10^{-11} \mathrm{M}$ neurotrophin. We agree with their conclusion that neurotrophins modulate growth cone responses to Sema3A.

As stated above, these studies are based on the idea that coincident signaling by Sema3A and neurotrophins occurs as DRG growth cones traverse tissues and within their targets. Several regions of chick and mouse embryos contain high Sema3A levels, such as the ventral spinal cord and epidermis (chicks) of their targets and the dermamyotome in the peripheral pathway. These regions are not entered by NGF-dependent axons. However, Sema3A is also broadly expressed at low levels in mesenchyme (Giger et al., 1996; Shepherd et al., 1996). It may be that the coincident expression of neurotrophins triggers signaling to offset Sema3A-mediated activation of collapse and allows axons to extend through mesenchyme. In this situation, neurotrophins do not direct growth but maintain growth cone motility and axonal growth. This is supported by evidence that axonal extension along peripheral pathways is halted or deficient when neu- 
rotrophins are absent or blocked (Patel et al., 2000; Tucker et al., 2001). Thus, a balance between signaling by Sema3A and neurotrophins may contribute to sensory axonal growth. When both factors are present at low to intermediate levels, axons grow in fascicles through tissues. When regions of high Sema3A expression are encountered, sensitive axons do not enter these regions, and when regions of high neurotrophin expression are encountered, such as in a target, other growth cone behaviors, such as axonal branching, are stimulated. Our experiments emphasize the significance of concentration in determining the outcome of coincident signaling by Sema3A and NGF, but in vivo concentrations of these molecules are unknown. In vitro experiments often use these molecules in soluble form. However, Sema3A and NGF are basic proteins, which may bind to negatively charged extracellular matrix components, and remain near their release sites. To determine whether these ideas are relevant, we must learn more about in vivo distributions and actions of Sema3A and neurotrophins.

\section{REFERENCES}

Cahoon-Metzger AM, Wang G, Scott SA (2001) Contribution of BDNF-mediated inhibition in patterning avian skin innervation. Dev Biol 232:246-254.

Cai D, Shen Y, De Bellard M, Tang S, Filbin MT (1999) Prior exposure to neurotrophins blocks inhibition of axonal regeneration by MAG and myelin via a cAMP-dependent mechanism. Neuron 22:89-101.

Davies SR, Reddy H, Caivano M, Cohen P (2000) Specificity and mechanism of action of some commonly used protein kinase inhibitors. Biochem J 351:95-105.

Dickson BJ (2001) Rho GTPases in growth cone guidance. Curr Opin Neurobiol 11:103-110.

Dong JM, Leung T, Manser E, Lim L (1998) CAMP-induced morphological changes are counteracted by the activated RhoA small GTPase and the Rho kinase ROKinase. J Biol Chem 273:22554-22562.

Eide AL, Glover JC (1997) Developmental dynamics of functionally specific primary sensory afferent projections in the chick embryo. Anat Embryol 195:237-250.

Elkabes S, Dreyfus CF, Schaar DG, Black IB (1994) Embryonic sensory development: local expression of neurotrophin-3 and target expression of nerve growth factor. J Comp Neurol 341:204-213.

Ernst AF, Gallo G, Letourneau PC, McLoon SC (2000) Stabilization of growing retinal axons by the combined signaling of nitric oxide and brain-derived neurotrophic factor. J Neurosci 20:1458-1469.

Essler M, Staddon JM, Weber PC, Aepfelbacher M (2000) Cyclic AMP blocks bacterial lipopolysaccharide-induced myosin light chain phosphorylation in endothelial cells through inhibition of Rho/ Rho kinase signaling. J Immunol 164:6543-6549.

Firestein BL, Bredt DS (1998) Regulation of sensory neuron precursor proliferation by cyclic GMP-dependent protein kinase. J Neurochem 71:1846-1853.

Fu SY, Sharma K, Luo Y, Raper JA, Frank E (2000) SEMA3A regulates developing sensory projections in the chicken spinal cord. J Neurobiol 45:227-236.

Gallo G, Letourneau PC (1998) Localized sources of neurotrophins initiate axon collateral sprouting. J Neurosci 18:5403-5414.

Gallo G, Lefcort FB, Letourneau PC (1997) The trkA receptor mediates growth cone turning toward a localized source of nerve growth factor. J Neurosci 17:5445-5454.

Gallo G, Ernst AF, McLoon SC, Letourneau PC (2002) Transient PKA activity is required for initiation but not maintenance of BDNFmediated protection from nitric oxide induced growth-cone collapse. J Neurosci 22:5016-5023.

Garthwaite J, Southam E, Boulton CL, Nielsen EB, Schmidt K, Mayer B (1995) Potent and selective inhibition of nitric oxide-sensitive quanylyl cyclase by $1 \mathrm{H}-[1,2,4]$ oxidiazolo[4,3-a]quinoxalin-1-one. Mol Pharmacol 48:184-188.

Giger RJ, Wolfer DP, De Wit GMJ, Verhaagen J (1996) Anatomy of rat semaphorin III/collapsin-1 mRNA expression and relationship to developing nerve tracts during neuroembryogenesis. J Comp Neurol 375:378-392.

He Z, Tessier-Lavigne M (1997) Neuropilin is a receptor for the axonal chemorepellent semaphorin III. Cell 90:739-751.

Hidaka H, Kobayashi R (1992) Pharmacology of protein kinase inhibitors. Annu Rev Pharmacol Toxicol 32:377-397.

Hoffmann F (2000) Rising behind NO: cGMP-dependent protein kinases. J Cell Sci 113:1671-1676.

Hopker VH, Shewan D, Tessier-Lavigne M, Poo M, Holt C (1999)
Growth-cone attraction to netrin-1 is converted to repulsion by laminin-1. Nature 401:69-73.

Jin Z, Strittmatter SM (1997) Rac1 mediates collapsin-1-induced growth cone collapse. J Neurosci 17:6256-6263.

Katoh K, Kano Y, Amamo M, Onishi H, Kaibuchi K, Fujiwara K (2001) Rho-kinase-mediated contraction of isolated stress fibers. J Cell Biol 153:569-583.

Knipper M, Beck A, Rylett J, Breer H (1993) Neurotrophin-induced cAMP and IP3 responses in PC12 cells. FEBS Lett 14:147-152.

Ko FN, Wu CC, Kuo SC, Lee FY, Teng CM (1994) YC-1, a novel activator of platelet guanylate cyclase. Blood 84:4226-4233.

Kobayashi H, Koppel AM, Luo Y, Raper JA (1997) A role for collapsin-1 in olfactory and cranial sensory axon guidance. J Neurosci $17: 8339-8352$.

Kolodkin AL, Levengood DV, Rowe EG, Tai YT, Giger RJ, Ginty DD (1997) Neuropilin is a semaphorin III receptor. Cell 90:753-762.

Kozma R, Sarner S, Ahmed S, Lim L (1997) Rho family GTPases and neuronal growth cone remodeling: relationship between increased complexity induced by $\mathrm{CDC} 42 \mathrm{Hs}$, Rac1 and acetylcholine and collapse induced by RhoA and lysophosphatidic acid. Mol Cell Biol 17:1201-1211.

Kranenburg O, Poland M, van Horck FP, Dreschel D, Hall A, Moolenaar WH (1999) Activation of RhoA by lysophosphatidic acid and $\mathrm{G} \alpha$ 12/13 subunits in neuronal cells: induction of neurite retraction. Mol Biol Cell 10:1851-1857.

Kuhn TB, Brown MD, Wilcox CL, Raper JA, Bamburg JR (1999) Мyelin and collapsin-1 induce motor neuron growth cone collapse through different pathways: inhibition of collapse by opposing mutants of Rac1. J Neurosci 19:1965-1975.

Lang P, Gesbert F, Delespine-Carmagnat M, Stancou R, Pouchelet M, Bertoglio J (1996) Protein kinase A phosphorylation of RhoA mediates the morphological and functional effects of cyclic AMP in cytotoxic lymphocytes. EMBO J 15:510-519.

Lee FS, Kim AH, Khursigara G, Chao MV (2001) The uniqueness of being a neurotrophin receptors. Curr Opin Neurobiol 11:281-286.

Letourneau PC (1996) The cytoskeleton in nerve growth cone motility and axonal pathfinding. Perspect Dev Neurobiol 4:111-123.

Luo Y, Raible D, Raper JA (1993) Collapsin: a protein in brain that induces the collapse and paralysis of neuronal growth cones. Cell 75:217-227.

Martin P, Khan A, Lewis J (1989) Cutaneous nerves of the chicken wing do not develop in regions devoid of ectoderm. Development 106:335-346.

Mendelson B, Koerber HR, Frank E (1992) Development of cutaneous and proprioceptive afferent projections in the chick spinal cord. Neurosci Lett 138:72-76.

Messersmith EK, Leonardo ED, Shatz CJ, Tessier-Lavigne M, Goodman CS, Kolodkin AL (1995) Semaphorin III can function as a selective chemorepellent to pattern sensory projections in the spinal cord. Neuron 14:949-959.

Ming G-L, Song H-J, Berninger B, Holt CE, Tessier-Lavigne M, Poo M-M (1997) cAMP-dependent growth cone guidance by netrin-1. Neuron 12:1225-1235.

Ming G-L, Song H-J, Berninger B, Inagaki N, Tessier-Lavigne M, Poo M-M (1999) Phospholipase C-gamma and phosphoinositide 3-kinase mediate cytoplasmic signaling in nerve growth cone guidance. Neuron 23:139-148

Muller BK (1999) Growth cone guidance: first steps towards a deeper understanding. Annu Rev Neurosci 22:351-388.

Nakamura F, Kalb RG, Strittmatter SM (2000) Molecular basis of semaphorin-mediated axon guidance. J Neurobiol 44:219-229.

Patapoutian A, Reichardt LF (2001) Trk receptors: mediators of neurotrophin action. Curr Opin Neurobiol 11:272-280.

Patel TD, Jackman A, Rice FL, Kucera J, Snider WD (2000) Development of sensory neurons in the absence of $\mathrm{NGF} /$ trkA signaling in vivo. Neuron 25:347-357.

Pond A, Roche FK, Letourneau PC (2002) Temporal regulation of neuropilin-1 expression and sensitivity to semaphorin $3 \mathrm{~A}$ in NGF- and NT3-responsive chick sensory neurons. J Neurobiol 51:43-53.

Puschel AW, Adams RH, Betz H (1996) The sensory innervation of the mouse spinal cord may be patterned by differential expression of and differential responsiveness to semaphorins. Mol Cell Neurosci 7:419-431.

Qian Y, Chao DS, Santillano DR, Cornwell TL, Nairn AC, Greengard P, Lincoln TM, Bredt DS (1996) cGMP-dependent kinase in dorsal root ganglion: relationship with nitric oxide synthase and nociceptive neurons. J Neurosci 16:3130-3138.

Redowicz MJ (1999) Rho-associated kinase: involvement in the cytoskeleton regulation. Arch Biochem Biophys 364:122-124.

Rhom B, Rahim B, Kleiber B, Hovatta I, Puschel AW (2000) The semaphorin $3 \mathrm{~A}$ receptor may directly regulate the activity of small GTPases. FEBS Lett 486:68-72.

Shepherd I, Luo Y, Raper JA, Chang S (1996) The distribution of collapsin-1 mRNA in the developing chick nervous system. Dev Biol 173:185-199. 
Shepherd IT, Luo Y, Lefcort F, Riechardt LF, Raper JA (1997) A sensory axon repellent secreted from ventral spinal cord explants is neutralized by antibodies raised against collapsin-1. Development 124:1377-1385.

Silveira LA, Smith JL, Tan JL, Spudich JA (1998) MLCK-A, an unconventional myosin light chain kinase from Dictyostelium is activated by a cGMP-dependent pathway. Proc Natl Acad Sci USA 95:13000-13005.

Snider WD (1994) Functions of the neurotrophins during nervous system development: what the knockouts are teaching us. Cell 77:627-638.

Song H-J, Poo M-M (1999) Signal transduction underlying growth cone guidance by diffusible factors. Curr Opin Neurobiol 9:355-363.

Song, H-J, Ming G-L, He Z, Lehmann M, McKerracher L, TessierLavigne M, Poo M-M (1998) Conversion of neuronal growth cone responses from repulsion to attraction by cyclic nucleotides. Science 281:1515-1518.

Stein E, Tessier-Lavigne M (2001) Hierarchical organization of guidance receptors: silencing of netrin attraction by slit through a Robo/ DCC receptor complex. Science 291:1928-1938.

Takagi S, Kasuya Y, Shimzu M, Masuura T, Tsuboi M, Kawakami A, Fugisawa H (1995) Expression of a cell adhesion molecule, neuropilin, in the developing chick nervous system. Dev Biol 170:207-222.

Takahashi T, Fournier A, Nakamura F, Wang LH, Murakami Y, Kalb RG, Fujisawa H, Strittmatter SM (1999) Plexin-neuropilin-1 complexes form functional semaphorin-3A receptors. Cell 99:59-69.

Taniguchi M, Yuasa S, Fujisawa H, Naruse I, Saga S, Mishina M, Yagi T (1997) Disruption of semaphorin III/D gene causes severe abnormality in peripheral nerve projection. Neuron 19:519-530.

Tucker KL, Meyer M, Barde YA (2001) Neurotrophins are required for nerve growth during development. Nat Neurosci 4:29-37.

Tuttle R, O'Leary DDM (1998) Neurotrophins rapidly modulate growth cone response to the axon guidance molecule, collapsin-1. Mol Cell Neurosci 11:1-8.

Vastrik I, Eickholt BJ, Walsh FS, Ridley A, Doherty P (1999) Sema3A- induced growth cone collapse is mediated by Rac1 amino acids 17-32. Curr Biol 9:991-998.

Vo NK, Gettemy JM, Coghlan VM (1998) Identification of cGMPdependent protein kinase anchoring proteins (GKAPs). Biochem Biophys Res Commun 246:831-835.

Wahl S, Barth H, Ciossek T, Aktories K, Muller BK (2000) Eprhin-A5 induces collapse of growth cones by activating Rho and Rho kinase. J Cell Biol 149:263-270.

Walsh DA, Glass DB (1991) Utilization of the inhibitor protein of adenosine cyclic monophosphate-dependent protein kinase and peptides derived from it, as tools to study adenosine cylic monophosphatemediated cellular processes. Methods Enzymol 201:304-316.

Ward SM, Shuttleworth CW, Kenyon JL (1994) Dorsal root ganglion neurons of embryonic chicks contain nitric oxide synthase and respond to nitric oxide. Brain Res 648:249-258.

White FA, Silos-Santiago I, Molliver DC, Nishimura M, Phillips H, Barbacid M, Snider WD (1996) Synchronous onset of NGF and TrkA survival dependence in developing dorsal root ganglia. J Neurosci 16:4662-4672.

Williams R, Ebendal T (1995) Neurotrophin receptor expression during development of the chick spinal ganglion. NeuroReport 6:2277-2282.

Wright DE, White FA, Gerfen RW, Silos-Santiago I, Snider WF (1995) The guidance molecule semaphorin III is expressed in regions of spinal cord and periphery avoided by growing sensory axons. J Comp Neurol 361:321-333.

Yamaguchi Y, Katoh H, Yasui H, Mori K, Negishi M (2001) RhoA inhibits the nerve growth factor-induced Rac1 activation through Rhoassociated kinase-dependent pathway. J Biol Chem 276:18977-18983.

Zhang Hl, Singer RH, Bassell GJ (1999) Neurotrophin regulation of beta-actin mRNA and protein localization within growth cones. J Cell Biol 147:59-70.

Zou Y, Stoeckli E, Chen H, Tessier-Lavigne (2000) Squeezing axons out of the gray matter: a role for slit and semaphorin proteins from midline and ventral spinal cord. Cell 102:363-375. 